Pathophysiology of Haemostasis and Thrombosis
Pathophysiol Haemost Thromb 2003/04;33:192-196

DOI: $\underline{10.1159 / 000081507}$
Received: February 25, 2004

Accepted after revision: June 22, 2004

\title{
Acquired and Inherited Thrombophilic Factors and the Risk for Residual Venous Thrombosis
}

\author{
Ivan Bank ${ }^{\mathrm{a}}$ Lidwine W. Tick $^{\mathrm{c}}$ Barbara A. Hutten ${ }^{\mathrm{b}}$ Mark H.H. Kramer \\ Saskia Middeldorp ${ }^{a}$ Harry R. Büller ${ }^{a}$ \\ Departments of ${ }^{a}$ Vascular Medicine and ${ }^{b}$ Clinical Epidemiology and Biostatistics, Academic Medical Center, \\ University of Amsterdam, Amsterdam and ${ }^{\mathrm{C}}$ Department of Internal Medicine, Eemland Hospital, \\ Amersfoort, The Netherlands
}

\section{Key Words}

Residual thrombosis - Location of thrombotic lesions • Deep venous thrombosis · Inherited thrombophilia • Acquired thrombophilia

\begin{abstract}
Acquired and inherited thrombophilic factors increase the risk for (recurrent) venous thrombotic disease. However, little is known about the pathophysiological mechanisms causing these recurrences, or the persistence of thrombosis despite adequate treatment. Because residual thrombosis has been associated with a worse prognostic outcome, we performed an explorative study in order to investigate the prevalence of residual thrombotic lesions after anticoagulant treatment in patients with deep venous thrombosis. Thrombotic parameters as assessed by ultrasonography after a 12-week course of anticoagulants were used. Both thrombophilia in general and acquired thrombophilia in particular were found to be associated with the extent of residual thrombosis. Of the individual thrombophilic factors, protein $\mathrm{C}$ deficiency, prothrombin 20210A mutation, active malignant disease and lupus anticoagulant were associated with an increased risk of residual thrombotic mass. Patients with
\end{abstract}

inherited thrombophilia did not differ from patients without any thrombophilic abnormality with regard to residual thrombotic mass [relative risk (RR) 1.3, 95\% confidence interval (CI) 0.9-1.8], while acquired thrombophilic disorders increased the risk for residual thrombotic mass as compared to patients without any defect (RR 1.7, 95\% $\mathrm{Cl}$ 1.2-2.2). Although these results should be confirmed in a larger study, they might help us form hypotheses concerning why patients with thrombophilia are more prone to recurrent venous thromboembolic disease.

Copyright $\odot 2004$ S. Karger AG, Basel

\section{Introduction}

Acquired and inherited thrombophilic factors are associated with a tendency to develop venous thromboembolism (VTE). Although it is known that some (acquired) thrombophilic states, for example the antiphospholipid syndrome, malignancy and elevated clotting factor VIII:c (FVIII:c), as well as persistence of thrombotic obstruction, increase the risk for recurrence of VTE, little is known about the pathophysiological mechanisms causing these recurrences [1-3].

\section{KARGER \\ Fax +4161306 1234 E-Mail karger@karger.ch} www.karger.com

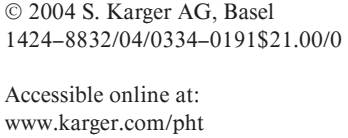

I. Bank

Department of Vascular Medicine, Academic Medical Center

F4-277, Meibergdreef 9

NL-1105 AZ, Amsterdam (The Netherlands)

Tel. +31 20 5665976, Fax +31 20 6968833, E-Mail I.Bank@amc.uva.nl 
Since residual thrombosis may be an important risk factor for recurrent thrombotic disease, it would be interesting to know whether the presence of thrombophilia influences the location and extension of thrombotic lesions and their recovery after treatment with antithrombotic agents [4]. One may hypothesize that thrombotic lesions of thrombophilic patients do not resolve as well as lesions in patients without such abnormalities.

To examine whether thrombophilia is associated with the extent of residual thrombosis after anticoagulant treatment, we used the data set of a clinical trial on secondary prophylaxis of VTE in patients with acute proximal deep venous thrombosis (DVT) of the leg [5].

\section{Patients and Methods}

\section{Study Population and Design}

Patients with symptomatic DVT from two Dutch teaching hospitals participating in a dose-finding study, described in detail elsewhere, comprised the study population [5]. In brief, this study was a multicenter, double-blind trial on the dose-effect relationship of subcutaneous long-acting pentasaccharide (Idraparinux, Organon, Oss, The Netherlands, and Sanofi-Synthelabo, Paris, France) versus an oral vitamin $\mathrm{K}$ antagonist (warfarin) in a 12-week treatment for secondary prophylaxis of VTE. Patients were randomized to either 2.5, 5, 7.5 or $10.0 \mathrm{mg}$ of Idraparinux or vitamin $\mathrm{K}$ antagonist after approximately 1 week of low-molecular-weight heparin (enoxaparin twice daily $0.1 \mathrm{ml} / \mathrm{kg}$ ). One of the primary efficacy outcome parameters was the composite of change in thrombotic burden as assessed by compression ultrasonography (CUS) and perfusion lung scanning.

Ultrasonography, using real-time B-mode with compression only, was performed using a standard 5- to $12-\mathrm{MHz}$ linear array transducer and was performed by the same radiologists in each center. Veins were scanned in the transverse plane only. In all patients, common femoral, superficial femoral and popliteal veins were evaluated, without attempts to identify isolated calf vein thrombosis [6, 7].

The first CUS was performed on the day on which Idraparinux or warfarin was started, and the second CUS was performed after 12 weeks of treatment.

Patients with a history of DVT in the ipsilateral leg to that in which acute DVT had been diagnosed could participate if complete normalization of thrombosis in that leg had been documented prior to the recurrent symptomatic DVT.

For the present analysis, all patients who had completed the study and in whom screening for thrombophilia had been performed were included. Since the study results showed a comparable efficacy outcome with respect to thrombotic burden (CUS and perfusion lung scan parameters together) in patients treated with 2.5, 5 or $7.5 \mathrm{mg}$ of Idraparinux and warfarin, these treatment arms were pooled and used for the present analyses.

\section{Residual Thrombotic Lesions}

The main outcome for this analysis was residual thrombus mass after 12 weeks of treatment as measured by CUS.
The thrombus location was defined by the location of non-compressibility at the level of the popliteal, superficial femoral or common femoral vein at the start and at the end of the 12-week treatment.

'Normalization' was defined as a diameter of less than or equal to $2 \mathrm{~mm}$ at one or more of the three sites. 'Deterioration' was defined as an increase in diameter of more than $2 \mathrm{~mm}$ or more than $25 \%$ at any site. Other results were classified as 'no relevant change'. 'Residual thrombus mass' was used to label the state of no full recovery of thrombus mass after 3 months of treatment.

\section{Screening for Thrombophilia}

Thrombophilia was defined as the presence of active malignant disease or the antiphospholipid syndrome (acquired thrombophilia) or having abnormal test results for other (hereditary) thrombophilic defects. Antithrombin deficiency, protein S deficiency, protein C deficiency, factor V Leiden mutation, prothrombin 20210A mutation, mild hyperhomocysteinemia and elevated FVIII:c were considered to be hereditary thrombophilic factors.

Antithrombin antigen concentrations were measured using the Asseraplate Antithrombin Kit (Boehringer, Mannheim, Germany) [8]. Protein C activity was measured using the Protein C Reagent Kit (Behringwerke, Marburg, Germany) [9]. Concentrations of total and free protein $\mathrm{S}$ were measured by ELISA using rabbit antiprotein $\mathrm{S}$ polyclonal antibody (DAKO, Glostrup, Denmark) and the $15 \mathrm{C} 4$ antiprotein S monoclonal antibody (Serbio, Gennevilliers, France) [10]. Lupus anticoagulant was determined using a panel of coagulation tests, including the activated partial thromboplastin time, the dilute Russell's viper venom time and the kaolin clotting time, while anticardiolipin antibodies were detected and quantified by ELISA [11]. Factor V Leiden mutation and prothrombin 20210A mutation were determined by standard polymerase chain reaction-based assays as described before [12, 13]. Homocysteine measurements including a loading test were performed. Total (free plus protein-bound) homocysteine concentrations were measured using tri-n-butylphosphine as reducing agent and ammonium 7-fluorobenzo-2-oxa-1,3-diazole-4-sulfate as the fluorochromophore, followed by high-pressure liquid chromatography with fluorescence detection [14]. FVIII:c was measured by a one-stage clotting assay, 3 months after the diagnosis of DVT [15].

The following reference values were used: antithrombin $80-$ $120 \%$; total protein S 65-120\%; free protein S 26-120\%; protein C activity 65-130\%; elevated FVIII:c $>150 \%$; homocysteine levels (fasting and after loading) in women $<18.3$ and $<56.2 \mu \mathrm{mol} / 1$, respectively, and in men $<16.9$ and $<47.0 \mu \mathrm{mol} / 1$, respectively.

Statistical Analysis

Patients with individual thrombophilic factors or with combinations of thrombophilic factors were compared to individuals without thrombophilia (reference population).

For the comparisons among patients with different thrombophilic factors, $\chi^{2}$ tests were applied to compare distributions of dichotomous data, and relative risks (RRs) and their corresponding $95 \%$ confidence intervals (CIs) were calculated. $p$ values of $<0.05$ were considered to be statistically significant. 


\section{Results}

\section{Study Population}

A total of 64 patients were eligible for analysis (44\% male, mean age 54 years). Table 1 lists the observed thrombophilic defects. One or more defects were found

Table 1. Thrombophilic factors in patients

\begin{tabular}{|c|c|}
\hline Any thrombophilic factor & $34(53)$ \\
\hline \multicolumn{2}{|l|}{ Thrombophilic factors } \\
\hline Factor V Leiden mutation ${ }^{1}$ & $13(20)$ \\
\hline Mild hyperhomocysteinemia & $12(19)$ \\
\hline Elevated FVIII:c & $11(17)$ \\
\hline Protein S deficiency & $3(5)$ \\
\hline Prothrombin 20210A mutation ${ }^{1}$ & $3(5)$ \\
\hline Positive anticardiolipin antibody IgG & $3(5)$ \\
\hline Positive anticardiolipin antibody IgM & $2(3)$ \\
\hline Protein $\mathrm{C}$ deficiency & $2(3)$ \\
\hline Lupus anticoagulant & $2(3)$ \\
\hline Active malignancy & $2(3)$ \\
\hline A combination of thrombophilic factors & $11(17)$ \\
\hline Inherited thrombophilia ${ }^{2}$ & $29(45)$ \\
\hline Acquired thrombophilia ${ }^{3}$ & $5(8)$ \\
\hline No thrombophilic factors & $30(47)$ \\
\hline
\end{tabular}

Values represent numbers of patients, with percentages in parentheses.

${ }^{1}$ All were heterozygous carriers.

${ }^{2}$ This group includes patients with protein $\mathrm{S}$ and $\mathrm{C}$ deficiency, factor V Leiden mutation, prothrombin 20210A mutation, mild hyperhomocysteinemia and elevated FVIII:c.

${ }^{3}$ This group includes patients with malignancy, positive lupus anticoagulant and positive anticardiolipin antibodies. in $53 \%$ of patients, while $42 \%$ of all patients had an inherited thrombophilic defect. Patients with thrombophilia were comparable to those without thrombophilia with respect to sex (male: 44 vs. $46 \%$, respectively; $p=0.7$ ) and age $(56 \pm 14$ vs. $51 \pm 17$ years, respectively; $p=0.2)$. Of the individual thrombophilic defects, factor $\mathrm{V}$ Leiden mutation was the most prevalent $(20 \%)$. Two patients (3\%) had an active form of malignant disease. None of the studied patients developed recurrent VTE during the study or 1-month follow-up period.

\section{Thrombotic Parameters}

There were no statistically significant ultrasonographic differences on the first CUS assessment between patients with and without thrombophilia.

Of the three locations, the popliteal vein was most frequently non-compressible on both CUS measurements (table 2). After 12 weeks of anticoagulant treatment, residual thrombotic lesions in the popliteal vein were more often present in patients with thrombophilia as compared to patients without thrombophilia (RR 2.3, 95\% CI 1.63.2). Furthermore, patients with acquired thrombophilia more often had residual thrombotic mass in the popliteal vein as compared to patients with inherited thrombophilia (RR 1.7, 95\% CI 1.2-2.3).

There were no differences in the states 'deterioration' or 'no relevant change' at the various locations when various groups were compared (thrombophilia vs. no thrombophilia; groups of thrombophilic disorders vs. no thrombophilia; individual thrombophilic defects vs. no thrombophilia). For example, 'deterioration' occurred in

Table 2. Locations of non-compressibility on the first and second CUS (CUS1 and CUS2)

\begin{tabular}{|c|c|c|c|c|c|c|}
\hline \multirow[t]{2}{*}{ Thrombophilic factor } & \multicolumn{2}{|c|}{$\begin{array}{l}\text { Non-compressibility } \\
\text { of popliteal vein }\end{array}$} & \multicolumn{2}{|c|}{$\begin{array}{l}\text { Non-compressibility of } \\
\text { superficial femoral vein }\end{array}$} & \multicolumn{2}{|c|}{$\begin{array}{l}\text { Non-compressibility of } \\
\text { common femoral vein }\end{array}$} \\
\hline & CUS1 & CUS2 & CUS1 & CUS2 & CUS1 & CUS2 \\
\hline Any thrombophilia & $30(88)$ & $23(68)$ & $19(56)$ & $15(44)$ & $9(27)$ & $7(21)$ \\
\hline Factor V Leiden mutation & $12(92)$ & $7(55)$ & $9(69)$ & $6(46)$ & $4(31)$ & $1(8)$ \\
\hline $\mathrm{MHH}$ & $10(83)$ & $8(67)$ & $6(50)$ & $2(17)$ & $5(42)$ & $2(17)$ \\
\hline Elevated FVIII:c & $9(82)$ & $8(74)$ & $7(64)$ & $4(36)$ & - & - \\
\hline Protein $\mathrm{S}$ deficiency & $2(67)$ & $2(67)$ & $2(67)$ & $2(67)$ & - & - \\
\hline Prothrombin mutation & $3(100)$ & $3(100)$ & $1(33)$ & $2(67)$ & $1(33)$ & $1(33)$ \\
\hline Protein $\mathrm{C}$ deficiency & $2(100)$ & $2(100)$ & $2(100)$ & $1(50)$ & - & - \\
\hline Lupus & $2(100)$ & $2(100)$ & $2(100)$ & $1(50)$ & $2(100)$ & $1(50)$ \\
\hline Active malignancy & $2(100)$ & $2(100)$ & $2(100)$ & $1(50)$ & - & - \\
\hline No thrombophilia & $22(73)$ & $9(30)$ & $13(43)$ & $11(37)$ & $14(47)$ & $12(40)$ \\
\hline
\end{tabular}

Values represent numbers of patients, with percentages of the total number of patients with each thrombophilic factor in parentheses. $\mathrm{MHH}=$ Mild hyperhomocysteinemia. 
$3 \%$ of all patients with thrombophilia as compared to $4 \%$ of patients without thrombophilia (RR 0.9, 95\% CI 0.24.1 ), and 'no relevant change' was found in $50 \%$ of all thrombophilic patients compared to $43 \%$ of patients without thrombophilia (RR 1.2, 95\% CI 0.9-1.6). Patients with one thrombophilic factor did not differ from patients without thrombophilic defects with respect to residual thrombotic mass on the second CUS (RR 1.3, 95\% CI 0.9-1.8). However, patients with three thrombophilic factors had an increased risk for residual thrombotic mass as compared to patients without thrombophilia (RR 1.7, 95\% CI 1.2-2.2).

Patients with inherited thrombophilia did not differ from patients without any thrombophilic abnormality (RR 1.3, 95\% CI 0.9-1.8), while acquired thrombophilic disorders increased the risk for residual thrombotic mass as compared to patients without thrombophilia (RR 1.7, 95\% CI 1.2-2.2). As compared to inherited thrombophilia, acquired thrombophilia increased this risk as well (RR $1.3,95 \%$ CI 1.1-1.6).

When patients with individual thrombophilic factors were compared to the control group, protein C deficiency, prothrombin 20210A mutation, lupus anticoagulant and active malignancy were risk factors for residual thrombotic mass at the second CUS (all RRs 1.7, 95\% CI 1.22.2). Transient risk factors for VTE (e.g. immobilization, use of oral contraceptives), use of pentasaccharide or warfarin, sex, age and weight were not associated with important effects on ultrasonographic thrombotic parameters.

\section{Discussion}

The results of this small hypothesis-generating study show that patients with thrombophilia, in particular acquired conditions, have an increased prevalence of residual thrombotic mass in the central venous tract after a 12-week course of antithrombotic therapy. Of the individual thrombophilic factors, protein $\mathrm{C}$ deficiency, prothrombin 20210A mutation, active malignant disease and lupus anticoagulant were associated with an increased risk of persistence of thrombotic burden.

Our findings may explain the observed increased recurrence risk in patients with malignancy or lupus anticoagulant and the observation in a recently published study that the risk for recurrence is considerably higher in patients with residual venous thrombosis on ultrasonography as compared to patients with complete normalization $[1,3,4]$. The prospective study performed by Prandoni et al. [4] found an association between throm- bophilia and residual thrombosis, but screening for thrombophilia was less extensive than in our study, patients with malignancy were not studied and the primary outcome was recurrent thromboembolic disease. Furthermore, that study was performed in a cohort of patients in whom treatment with anticoagulants had been discontinued, while the effect of treatment on the various thrombotic lesions could be better evaluated in our study.

Several issues warrant comment. First, our findings need to be confirmed in a larger study. Second, we used a subsample of screened patients with DVT participating in a randomized clinical study, which may raise concerns about the generalizability of our results. However, the observed prevalence of thrombophilic defects in our study sample was consistent with that in large cohorts of consecutive patients with VTE, and our study population appears to be adequate for this hypothesis-generating study [16].

The mechanisms by which various thrombophilic disorders cause persistence of thrombotic lesions, however, remain unknown and should be investigated in further research.

In conclusion, patients with (in particular acquired) thrombophilia appear to have an increased prevalence of residual thrombotic mass even while still using anticoagulant drugs, and this may explain their higher risk for recurrent venous thrombosis. 


\section{References}

1 Schulman S, Svenungsson E, Granqvist S: Anticardiolipin antibodies predict early recurrence of thromboembolism and death among patients with venous thromboembolism following anticoagulant therapy. Duration of Anticoagulation Study Group. Am J Med 1998; 104:332-338.

-2 Kyrle PA, Minar E, Hirschl M, Bialonczyk C, Stain M, Schneider B, Weltermann A, Speiser W, Lechner K, Eichinger S: High plasma levels of factor VIII and the risk of recurrent venous thromboembolism. N Engl J Med 2000;343: 457-462.

$\checkmark 3$ Levitan N, Dowlati A, Remick SC, Tahsildar HI, Sivinski LD, Beyth R, Rimm AA: Rates of initial and recurrent thromboembolic disease among patients with malignancy versus those without malignancy. Risk analysis using Medicare claims data. Medicine (Baltimore) 1999; 78:285-291.

4 Prandoni P, Lensing AW, Prins MH, Bernardi E, Marchiori A, Bagatella P: Residual venous thrombosis as a predictive factor of recurrent venous thromboembolism. Ann Intern Med 2002; 137:955-960.

5 The Persist investigators: A novel long-acting synthetic factor Xa inhibitor (SanOrg34006) to replace warfarin for secondary prevention in deep vein thrombosis. A phase II evaluation. J Thromb Haemost 2004;2:47-53.
6 Cogo A, Lensing AW, Koopman MM, Piovella F, Siragusa S, Wells PS, Villalta S, Buller HR, Turpie AG, Prandoni P: Compression ultrasonography for diagnostic management of patients with clinically suspected deep vein thrombosis: Prospective cohort study. BMJ 1998;316:17-20.

7 Lensing AW, Prandoni P, Brandjes D, Huisman PM, Vigo M, Tomasella G, Krekt J, ten Cate JW, Huisman MV, Buller HR: Detection of deep-vein thrombosis by real-time B-mode ultrasonography. N Engl J Med 1989;320:342345.

-8 Michiels JJ, Hamulyak K: Laboratory diagnosis of hereditary thrombophilia. Semin Thromb Hemost 1998;24:309-320.

-9 Sturk A, Morrien-Salomons WM, Huisman MV, Borm JJ, Buller HR, ten Cate JW: Analytical and clinical evaluation of commercial protein C assays. Clin Chim Acta 1987;165: 263-270.

10 Deutz-Terlouw PP, Ballering L, van Wijngaarden A, Bertina RM: Two ELISA's for measurement of protein $\mathrm{S}$, and their use in the laboratory diagnosis of protein $\mathrm{S}$ deficiency. Clin Chim Acta 1990;186:321-334.

11 Guidelines on testing for the lupus anticoagulant. Lupus Anticoagulant Working Party on behalf of the BCSH Haemostasis and Thrombosis Task Force. J Clin Pathol 1991;44:885889.
12 Bertina RM, Koeleman BP, Koster T, Rosendaal FR, Dirven RJ, de Ronde H, van der Velden PA, Reitsma PH: Mutation in blood coagulation factor $\mathrm{V}$ associated with resistance to activated protein C. Nature 1994;369:6467.

13 Danneberg J, Abbes AP, Bruggeman BM, Engel H, Gerrits J, Martens A: Reliable genotyping of the G-20210-A mutation of coagulation factor II (prothrombin). Clin Chem 1998;44: 349-351.

14 Ubbink JB, Hayward VW, Bissbort S: Rapid high-performance liquid chromatographic assay for total homocysteine levels in human serum. J Chromatogr 1991;565:441-446.

15 Koster T, Blann AD, Briet E, Vandenbroucke JP, Rosendaal FR: Role of clotting factor VIII in effect of von Willebrand factor on occurrence of deep-vein thrombosis. Lancet 1995; 345:152-155.

16 Middeldorp S, Buller HR, Prins MH: Approach to the thrombophilic patient; in Colman RW, Hirsch JL, Marder VJ, Clowes AW, George JN (eds): Hemostasis and Thrombosis: Basic Principles and Clinical Practice, ed 4. Philadelphia, Lippincott-Raven, 2000, pp 1085-1100. 